\title{
Induction Heating of Two Magnetically Independent Loads with a Single Transmitter
}

\author{
Emilio Plumed, Student Membership, Ignacio Lope, Membership, Jesús Acero, Senior Membership, and \\ José Miguel Burdío, Senior Membership
}

\begin{abstract}
This paper introduces the design of a system capable to heat two magnetically independent ferromagnetic loads, placed on different horizontal planes, that uses a combination of induction heating and inductive coupling, called inductively coupled heating. The system uses a single primary inductor acting as transmitter to nofer wer to a secondary inductor attached to the tom, 5 upled load, which is $D$ pected electrically with a third ductor that heats the independent load. Since no ore degrees of freedom are added, the delivered power to the second zone is entirely dependant on the system's geometry, materials and compensation capacitors. Therefore, the ratio of the delivered power to each of the zones becomes very relevant to the design. A finite element model is used to simulate the magnetic fields generated by inductor currents and calculate the impedance matrix. With the impedance, capacitor values and inductors' number of turns are selected with the objective of achieving a high power ratio between the top and bottom zone, as well as minimizing stress in the electronics. A prototype was built to validate the impedance results in the small signal regime first and then the full power regime was used to verify power and current simulations.
\end{abstract}

Index Terms-Induction Heating, Inductive Coupling, Home Appliances, Finite Element Method, Electromagnetic Analysis.

\section{INTRODUCTION}

I NDUCTION heating applied in a household environment is an advanced technological solution, actively researched on for more than 35 years [2]-[4]. The successive developments have made induction heating cooktops efficient [5]-[8], safe [9], fast and easy to use and clean [10], as well as adding flexibility regarding the material of cooking vessels [11], and their size and number [12]-[18]. These features have turned induction cooktops into a widely accepted industrial product.

In these cooktops, energy is transferred through electromagnetic induction directly from its inductors to the vessel without

This work is an extension of a conference paper [1].

This work was partly supported by the Spanish MICINN and AEI under Project PID2019-103939RB-I00, co-funded by EU through FEDER program, by the BSH Home Appliances Group and by the Gobierno de Aragón-FSE 2014-20 under Grant IIU/2023/2017.

Emilio Plumed, Jesús Acero and José Miguel Burdío are with the Department of Electronic Engineering and Communications, I3A, Universidad de Zaragoza, Zaragoza, Aragón, Spain, (e-mail: eplumed@unizar.es).

Ignacio Lope is with BSH Electrodomésticos España, Zaragoza, Aragón, Spain. He is also with the Department of Applied Physics, Universidad de Zaragoza, Zaragoza, Aragón, Spain.

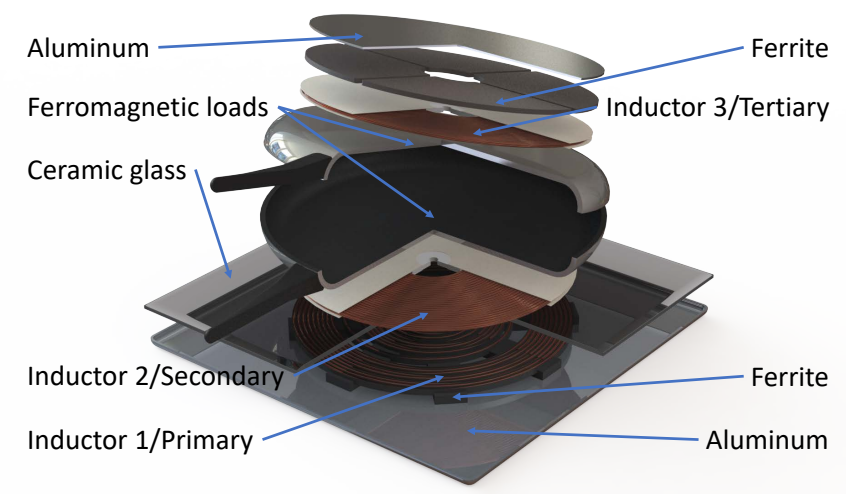

Fig. 1. Exploded system geometry.

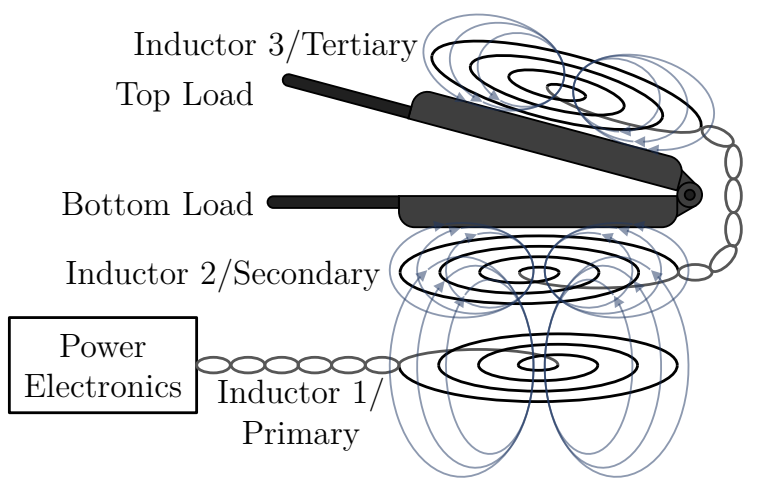

Fig. 2. Inductor connections diagram.

needing physical contact among its components [19], [20]. In a similar manner, Wireless Power Transfer (WPT) systems also use electromagnetic induction to transfer energy from a transmitting coil to a receiving coil [21]-[23], with continuous advances in topologies and control [24]-[26] and coil design [27].

Typical WPT applications use additional power electronics in their receiver side, such as rectifiers and DC/DC stages, to better control output voltage and power and make them immune to load variation and system misalignment. Currently, there is an increasing demand for small appliances that use WPT technology, and many of them require heating. Moreover, induction heating (IH) cooktops already have planar inductors that can transmit power wirelessly to other planar inductors. Additionally, some of these appliances require heat- 


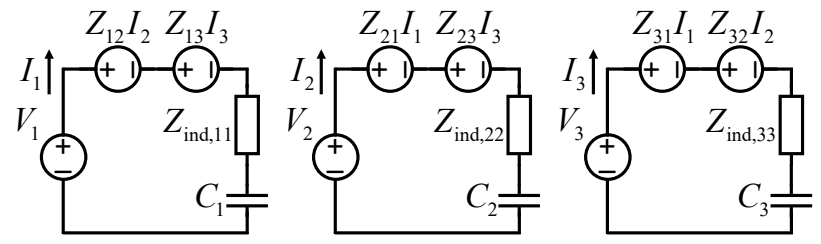

(a)

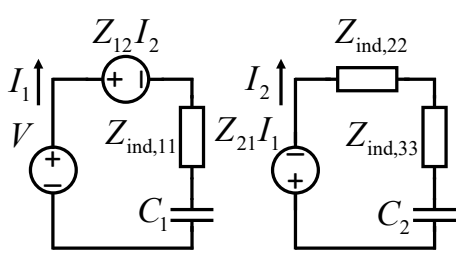

(b)

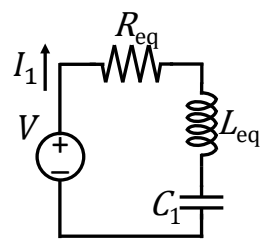

(c)

Fig. 3. Circuit diagrams: (a) generic three-inductor (b) proposed system's simplified circuit (c) inverter equivalent impedance circuit.

ing areas independent from its bottom surface, unreachable by IH alone or other conventional cooking technologies, such as gas or electric glass-ceramic.

Hybrid systems can transfer energy from inductor to inductor, while simultaneously heating ferromagnetic loads. Since IH and WPT can operate at the same frequencies, rectification and further inversion are redundant, and the additional electronics in the receiver side can be removed.

This kind of hybrid system can be used to create cordless portable ovens and double-sided pans where both upper and lower baking sheets are heated simultaneously, as shown in Fig. 1 and Fig. 2. The main advantages of this kind of cooking appliance are their enclosed space to prevent heat loss, like an oven, and their small volume to reduce energy requirements. Instead of flipping manually to keep both sides heated, the proposed system will heat both si pimultaneously, with a single correct "upright" position.

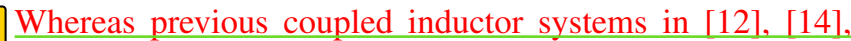
6]. [18] actively feed all inductors, the proposed system's receiver will not have an internal power source or external cables. Therefore, its only means to heat the top load will be the magnetic coupling with the inductor of a conventional induction heating cooktop.

Inductively coupled heating (ICH), defined as the combination of IH and magnetic coupling, has been used to improve working conditions for previously inefficient situations in conventional IH [28]-[30], and also to give new, inductively coupled functionality [1], [31]-[33]. Other works offer both IH and wireless magnetic coupling functionality independent of one another [34]. In this case, a system with an additional magnetically independent cooking zone is proposed, where only a single inductor is fed externally to heat a coupled, bottom load and transmit power to a secondary inductor which in turn is electrically connected to a third coil to heat an independent, top load. Essentially, a single primary cooktop inductor is to deliver power to two different loads simultaneously, re their position prevents coupling between receivers. In the case of Fig. 1, the uncoupled heating zone is the top cover of a small, slim oven. In its current form, the first and second inductors need to be aligned, and the bottom cooking zone is placed just above the secondary inductor. Nevertheless, the third inductor and top cooking zone or vessel can be placed anywhere, requiring only an electric connection to the secondary coil as depicted in the diagram in Fig. 2.

The objective of this paper, as an extension of the work presented in [1], is to design and test a $210 \mathrm{~mm} \varnothing \mathrm{ICH}$ system capable to deliver $3000 \mathrm{~W}$ to two ferromagnetic loads, where at least $50 \%$ of the power is transferred to the uncoupled top load. This requirement ensures that the system can give more heat to the top load, in order to cook meals that need higher temperature on the top, and to correct imbalances in processes that require homogeneous temperature. The position of the loads prevents coupling between their corresponding inductors and thus requires an electrical con $\Omega$ on. The system must also work in conjunction with a ermereial IH cooktop to reduce cost, and so that the secondary inductor itself does not need a cord to connect to the mains, an inverter topology or bulky filters.

The power flow in the system goes as follows: the induction heating cooktop feeds the primary inductor, which simultaneously heats the bottom load and transfers power to the second inductor. The second inductor contributes to heating the bottom load and is electrically connected to the third inductor. The third inductor's sole purpose is to heat the top load.

The main contribution of this work is the transfer of more than half the total power to the top load using only one energized inductor with impedance tuning and no additional active components, despite the fact that there are inductors beneath the bottom load and the top load and inductor are electromagnetically uncoupled from the rest of the system. No current commercial induction heating appliance can transmit power simultaneously to both halves of a double-sided pan. Though there are works that use the same technology, to the best of our knowledge, no similar enough systems have been proposed in the literature.

The rest of the paper is organized as follows. Section II introduces the system's circuit model and its most relevant parameters. The system's simulation and FEA tool are explained in Section III. Section IV introduces the experimental verification and simulation validation. Section $\mathrm{V}$ presents the conclusions drawn from this work.

\section{SYSTEM MODEL}

The modelled system depicted in Fig. 1 consists of a $210 \mathrm{~mm} \varnothing$ primary inductor with ferrite bars and an aluminum tray, a $210 \mathrm{~mm} \varnothing$ secondary inductor attached to the bottom ferromagnetic load and a third inductor of the same size attached to the top ferromagnetic load. The first and second inductors are separated by ceramic glass and the third inductor has a ferrite plane and a second aluminum tray above it for magnetic shielding.

The circuit diagram of a generic three inductor system is shown in Fig. 3 (a). Throughout most of the paper, the 


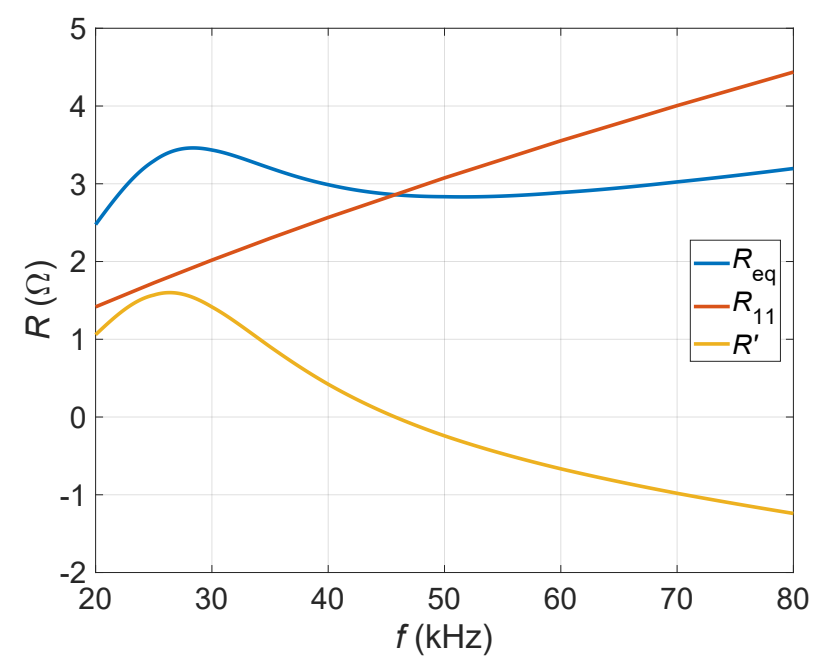

(a)

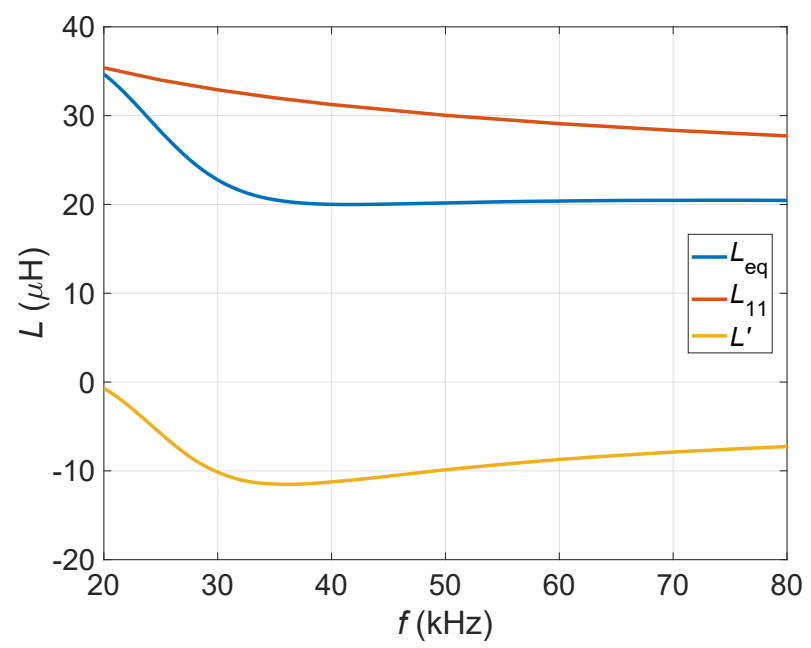

(b)

Fig. 4. Equivalent resistance (a) and inductance (b) breakdown according to (12) and (13).

calculations use phasors in the frequency domain, assuming that only the first order harmonic is relevant. This circuit can be expressed in the form of a matrix equation [14]:

$$
\left(\begin{array}{lll}
Z_{11} & Z_{12} & Z_{13} \\
Z_{21} & Z_{22} & Z_{23} \\
Z_{31} & Z_{32} & Z_{33}
\end{array}\right)\left(\begin{array}{l}
I_{1} \\
I_{2} \\
I_{3}
\end{array}\right)=\left(\begin{array}{l}
V_{1} \\
V_{2} \\
V_{3}
\end{array}\right),
$$

where $I_{i}$ is the current of the $i t h$ inductor, $V_{i}$ is its external voltage and $Z_{i j}$ the elements of the impedand $\rightarrow$ trix, where $Z_{i i}$ is the self impedance of the $i t h$ inductor, of the compensation capacitor, $C_{i}$, if present, and $Z_{i j}$ is the mutual impedance between inductors:

$$
\begin{gathered}
Z_{i i}=Z_{\text {ind }, i i}+1 / j \omega C_{i}=R_{i i}+j \omega L_{i i}+1 / j \omega C_{i}, \\
Z_{i j}=Z_{\text {ind }, i j}=R_{i j}+j \omega L_{i j}, i \neq j,
\end{gathered}
$$

where the involved terms are shown in Fig. 3 (a). Coupling factors can be defined for mutual inductance and resistance, $k_{l, i j}$ and $k_{r, i j}$ respectively:

$$
\begin{aligned}
k_{l, i j} & =L_{i j} / \sqrt{L_{i i} L_{j j}}, \\
k_{r, i j} & =R_{i j} / \sqrt{R_{i i} R_{j j}} .
\end{aligned}
$$

In this case, the second and third inductors are connected in series. Therefore only two resonant capacitors are needed, one for the primary inductor and another for the receiver side, that is, the series connected second and third inductors. The equations can then be simplified, as the current running through both inductors is the same and the voltage sum is zero since there is no external feed:

$$
\begin{gathered}
I_{2}=I_{3}, \\
V_{2}+V_{3}=0 .
\end{gathered}
$$

Therefore, the reduced order equation system is:

$$
\left(\begin{array}{cc}
Z_{11} & Z_{12}+Z_{13} \\
Z_{21}+Z_{31} & Z_{22}+2 Z_{23}+Z_{33}
\end{array}\right)\left(\begin{array}{c}
I_{1} \\
I_{2}
\end{array}\right)=\left(\begin{array}{c}
V_{1} \\
0
\end{array}\right) .
$$

In this system, the third inductor will heat a load inaccessible to the first two, as both loads are magnetically independent. Consequently, the terms $Z_{13}$ and $Z_{23}$ are considered negligible, which will also be verified in the simulations. The equations can then be simplified to:

$$
\left(\begin{array}{cc}
Z_{11} & Z_{12} \\
Z_{21} & Z_{22}+Z_{33}
\end{array}\right)\left(\begin{array}{c}
I_{1} \\
I_{2}
\end{array}\right)=\left(\begin{array}{c}
V_{1} \\
0
\end{array}\right)
$$

and the resulting simplified circuit is shown in Fig. 3 (b). Moreover, the magnetic independence of the top load and third inductor makes $Z_{33}$ the only impedance matrix element related to the top load. $Z_{11}, Z_{12}$ and $Z_{22}$ all relate to the bottom load.

The primary inductor is fed by a half-bridge inverter [10], forming the $L C$ series resonant tank by connecting the primary inductor to its capacitor. Therefore, a global equivalent impedance [29], $Z_{\mathrm{eq}}=V_{1} / I_{1}$, can be defined from the inverter's point of view:

$$
\begin{gathered}
Z_{\text {eq }}=Z_{11}-\frac{Z_{12}^{2}}{Z_{22}+Z_{33}}, \\
Z_{\text {eq }}=R_{\text {eq }}+j\left(\omega L_{\text {eq }}-1 / \omega C_{1}\right),
\end{gathered}
$$

where $R_{\text {eq }}$ is the equivalent resistance and $L_{\text {eq }}$ is the equivalent inductance. The resulting equivalent circuit is shown in Fig. 3 (c). Developing (10) and (11), the full expressions of $R_{\mathrm{eq}}$ and $L_{\mathrm{eq}}$ are:

$$
\begin{array}{r}
R_{\mathrm{eq}}=R_{11}+\underbrace{\frac{2 R_{12} \omega L_{12}\left(\omega L_{\mathrm{rec}}-\frac{1}{\omega C_{2}}\right)-\left(R_{12}^{2}-\omega^{2} L_{12}^{2}\right) R_{\mathrm{rec}}}{R_{\mathrm{rec}}^{2}+\left(\omega L_{\mathrm{rec}}-\frac{1}{\omega C_{2}}\right)^{2}}}_{R^{\prime}}, \\
L_{\mathrm{eq}}=L_{11}+\underbrace{\frac{2 R_{12} \omega L_{12} R_{\mathrm{rec}}-\left(R_{12}^{2}-\omega^{2} L_{12}^{2}\right)\left(\omega L_{\mathrm{rec}}-\frac{1}{\omega C_{2}}\right)}{\omega\left(R_{\mathrm{rec}}^{2}+\left(\omega L_{\mathrm{rec}}-\frac{1}{\omega C_{2}}\right)^{2}\right)}}_{L^{\prime}},
\end{array}
$$




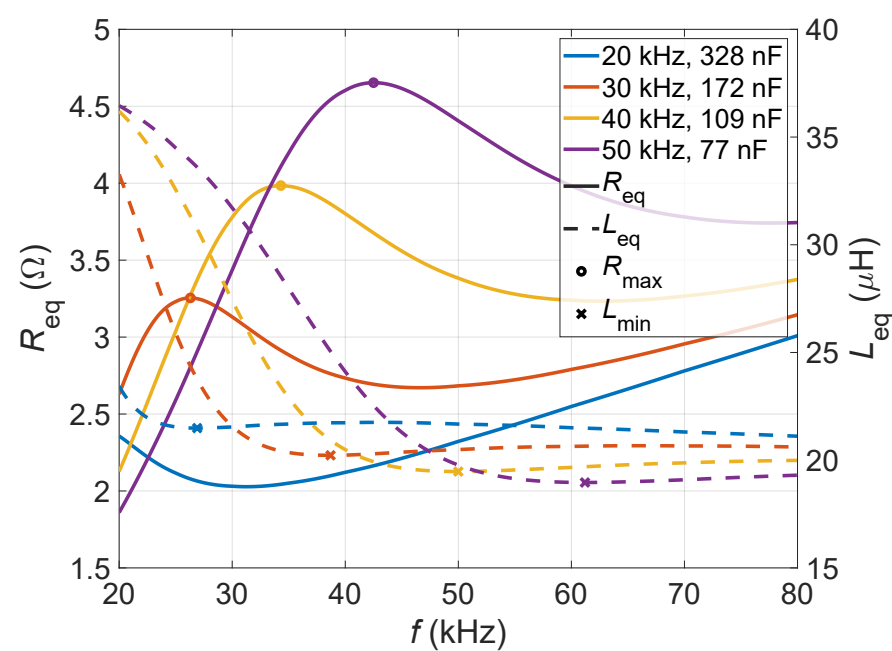

Fig. 5. Simulated equivalent resistance and inductance versus frequency for different $\omega_{0, \text { rec }}$, with specific $C_{2}$ values.

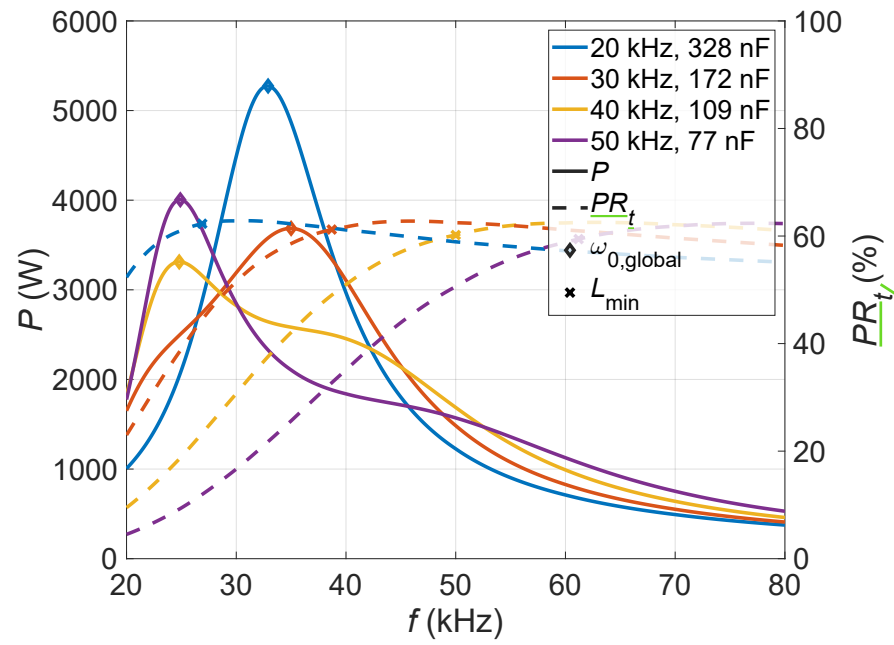

Fig. 6. Simulated total power and percentage of power delivered to the top load versus frequency for different $\omega_{0, \text { rec }}$.

where $R_{\text {rec }}=R_{22}+R_{33}, L_{\text {rec }}=L_{22}+L_{33}$ and $R^{\prime}, L^{\prime}$ are the resistance and inductance reflected to the primary side. For visual reference, the contributions of the elements $R_{11}$, $R^{\prime}$, and $L_{11}, L^{\prime}$ to $R_{\mathrm{eq}}$ and $\bigcirc$ respectively are represented in Fig. 4. $R^{\prime}$ increases $R_{\mathrm{eq}}$ in eak, and decreases it in others. $L^{\prime}$ only decreases $L_{\text {eq }}$, as datt elow 20kHz is not she with a minimum valley close to the $R_{\text {eq }}$ peak. Moreover, global resonant frequency, $\omega_{0, \text { eq }}$, can also be determined from (11):

$$
\omega_{0, \mathrm{eq}}=1 / \sqrt{L_{\mathrm{eq}} C_{1}} .
$$

Similarly, the receiver side composed of the second and third inductors with the second compensation capacitor have their own resonant frequency, $\omega_{0, \text { rec }}$, defined as [29], [33]:

$$
\omega_{0, \text { rec }}=1 / \sqrt{\left(L_{22}+L_{33}\right) C_{2}},
$$

which is very relevant for the equivalent impedance and other parameters, as $C_{2}$ appears in the expressions for both $R_{\mathrm{eq}}$ (12) and $L_{\mathrm{eq}}$ (13). Fig. 5 shows simulated impedance values for the proposed system, changing $C_{2}$ and keeping the values of the number of turns and $C_{1}$ constant. The values of $C_{2}$ are determined using (15) to achieve the stated $\omega_{0, \text { rec }}$ for each color. As shown, the impedance can be in the same order of magnitude than the values of a typical domestic induction heating application [7]. Moreover, both $R_{\text {eq }}$ and $L_{\text {eq }}$ are strongly dependent with frequency, with maximum and minimum values marked with circles and crosses respectively. Maximum $R_{\text {eq }}$ values are found slightly to the left of $\omega_{0 \text {,rec }}$ while minimum $L_{\mathrm{eq}}$ values are found slightly to the right.

These extreme values of impedance close together in frequency also ${ }^{\mathrm{c}}$ other derived values, such as the poyatio, $P R_{t}, D$ ween the top ferromagnetic load poyer $P_{10}$, and total transferred power, $P_{\text {total }}$, defined as $P R, Q$ $P_{\text {load }} \& D$ otal. Top power ratio, $P R_{\underline{t}}$, is simply an indicator of the power split between the top and bottom load and should not be confused with efficiency, defined as $\eta=P_{\text {losses }} / P_{\text {total }}$. Expressions for the losses' elements can be found in [7], [13]. $P R_{\underline{\underline{t}}}$ can be expressed in terms of current ratios and impedances:

$$
P R_{t}=\frac{P_{\text {loo }} \Omega}{P_{\text {total }}}=\frac{R_{33}\left|I_{3}\right|^{2}}{R_{\text {eq }}\left|I_{1}\right|^{2}}=\frac{R_{33}\left|Z_{21}\right|^{2}}{R_{\mathrm{e}}\left|Z_{22}+Z_{33}\right|^{2}},
$$

considering that $P_{\text {total }}=P_{10} \Omega-P_{10} \Omega P_{\text {where }} P_{\text {load, } b}$ is the power delivered to the bottom load. $P R_{t}$ has a maximum value at frequencies close to the inductance minimums, as shown in Fig. 6 for the same parameters of Fig. 5. The shift of $\omega_{0, \text { rec }}$ causes a change in $L_{\mathrm{eq}}$, as explained previously, which in turn causes a change in $\omega_{0 \text {,eq }}$ from $35 \mathrm{kHz}$ to $25 \mathrm{kHz}$.

In Fig. 6 it also be seen that for most of the power curve, the ratio lmost constant at $60 \%$, so this design is most suitable for applications where the power ratio needs to remain nearly constant for all delivered power values.

A degree of independent power control can be achieved using a switch on the receiver side. The switch would enable alternating the power split between $100 \%-0 \%$ and $40 \%-$ $60 \%$. Time averages can be used to reach intermediate ratios.

\section{SYSTEM SiMULATION}

\section{A. Finite Element Analysis}

In order to obtain the impedance matrix, the system was simulated in Comsol Multiphysics. The $210 \mathrm{~mm} \varnothing$ inductors are modelled as low losses disks with a uniform current density distributed in a single turn and the ferromagnetic loads as impedance boundary conditions [35]. The material properties for the loads are the same as those found in [14]. They are characteristic of the material that will be used for testing at $100{ }^{\circ} \mathrm{C}$. The impedance relation between single-turn and multiturn coils is [7]:

$$
Z_{i j}=n_{i} n_{j} Z_{i j \text {,s.t. }},
$$

where $n_{i}$ is the number of turns of the $i$ th inductor and $Z_{i j \text {,s.t. }}$ is the single turn impedance of element $i j$. For this to remain true when $i=j$, capacitor values also need to change with the number of turns:

$$
C_{i}=C_{i, \text { s.t. }} / n_{i}^{2},
$$




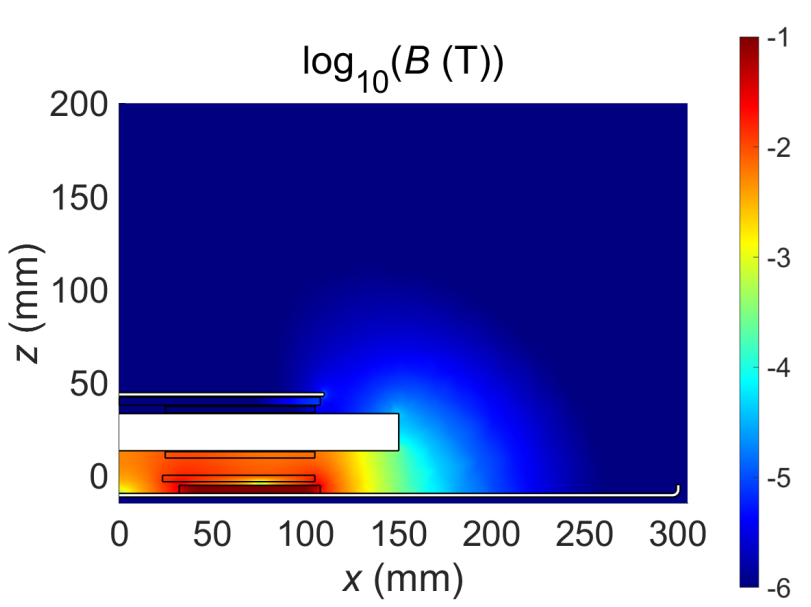

(a)

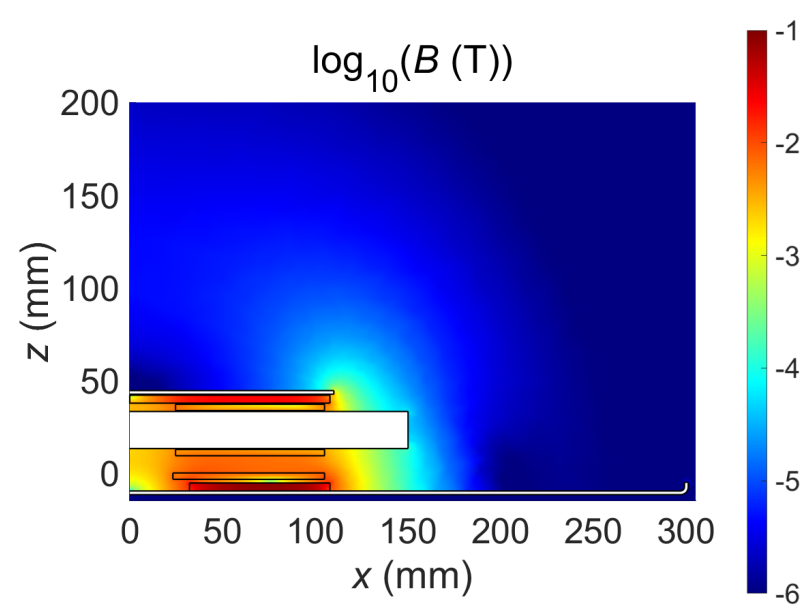

(b)

Fig. 7. Simulated magnetic field to deliver $3000 \mathrm{~W}$ (a) First inductor only (b) Full ICH system.

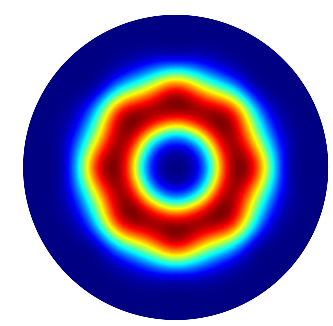

(a)

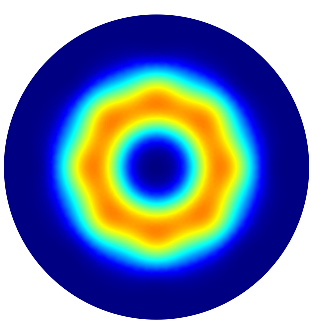

(b)

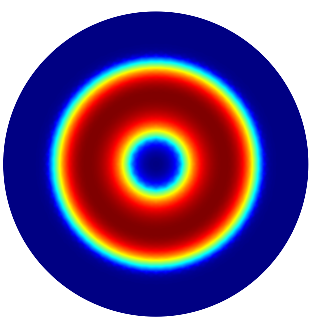

(c)
Fig. 8. Simulated power density to deliver $3000 \mathrm{~W}$ (a) First inductor only (b) Full ICH system bottom (c) Full ICH system top.

TABLE I

RESISTANCE VALUES OF THE IMPEDANCE MATRIX AT $30 \mathrm{KHZ}$

\begin{tabular}{lccc}
\hline$i$ & $R_{i 1 \text {,s.t. }}(\mathrm{m} \Omega)$ & $R_{i 2 \text {,s.t. }}(\mathrm{m} \Omega)$ & $R_{i 3 \text {,s.t. }}(\mathrm{m} \Omega)$ \\
\hline$R_{1 j \text {,s.t. }}$ & 6.72 & 8.59 & 0.00202 \\
$R_{2 j \text {,s.t. }}$ & 8.59 & 11.1 & 0.00187 \\
$R_{3 j \text {,.t. }}$ & 0.00202 & 0.00187 & 18.8 \\
\hline
\end{tabular}

where $C_{i \text {,s.t. }}$ is a mathematical single-turn capacitor [29] that enables the relation:

$$
X_{i i}=n_{i}^{2}\left(\omega L_{i i \text {,.t. }}-1 / \omega C_{i, \text { s.t. }}\right)=n_{i}^{2} X_{i i \text {,s.t. }},
$$

where $X_{i i}$ is the reactance of the $i i$ matrix element and $X_{i i \text {,s.t. }}$ the single-turn reactance.

Each element of the impedance matrix, $Z_{\text {ind }, i j, \text { s.t. }}$, is obtained by driving an external current through inductor $i$ and computing induced voltage in inductor $j$ [12].
TABLE II

INDUCTANCE VALUES OF THE IMPEDANCE MATRIX AT $30 \mathrm{KHZ}$

\begin{tabular}{lccc}
\hline$i$ & $L_{i 1 \text {,s.t. }}(\mathrm{nH})$ & $L_{i 2 \text {,s.t. }}(\mathrm{nH})$ & $L_{i 3 \text {,s.t. }}(\mathrm{nH})$ \\
\hline$L_{1 j \text {,s.t. }}$ & 114 & 76.2 & 0.00671 \\
$L_{2 j \text {,s.t. }}$ & 76.2 & 97.4 & 0.00891 \\
$L_{3 j \text {,s.t. }}$ & 0.00671 & 0.00891 & 110 \\
\hline
\end{tabular}

Impedance results at $30 \mathrm{kHz}$ are shown in Tables I and II for the simulated geometry of $210 \mathrm{~mm} \varnothing$ inductors shown in Fig. 7 , where the simplification made in (9) is justified. Applying (4) and (5), the coupling factors for the table values are $k_{l, 12}=$ 0.7231 and $k_{r, 12}=0.9946$. As expected, the symmetry in the impedance matrix, that is, the relation $Z_{i j}=Z_{j i}$, is also verified.

Fig. 7 represents the simulated magnetic field generated, first by only the first inductarnd then by the full ICH system when delivering $3000 \mathrm{~W}$.

Fig. 8 represents the liated power distribution in the loads, first by only the fin 2 ductor and then by the full ICH system when delivering $3000 \mathrm{~W}$.

\section{B. System Design}

The finite element simulation has provided the single turn inductor elements of the impedance matrix. Now it remains to select the number of turns of each inductor and the capacitor values. As part of a half-bridge $\mathrm{IH}$ appliance, the power is frequency-controlled. Consequently, the ICH system needs to have a monotonic relation between frequency and power, from $0 \mathrm{~W}$ to $3000 \mathrm{~W}$.

As the system must be compatible with an existing $\mathrm{IH}$ cooktop, the capacitor value and inductor number of turns on the primary side are predetermined. For this paper, the values that can be changed by design are the number of turns of the second and third inductors, as well as the second resonant capacitor.

In order to operate at a relatively constant $P R_{\underline{t}}$, the working frequencies have to be greater than those of the maximum $R_{\mathrm{eq}}$ 


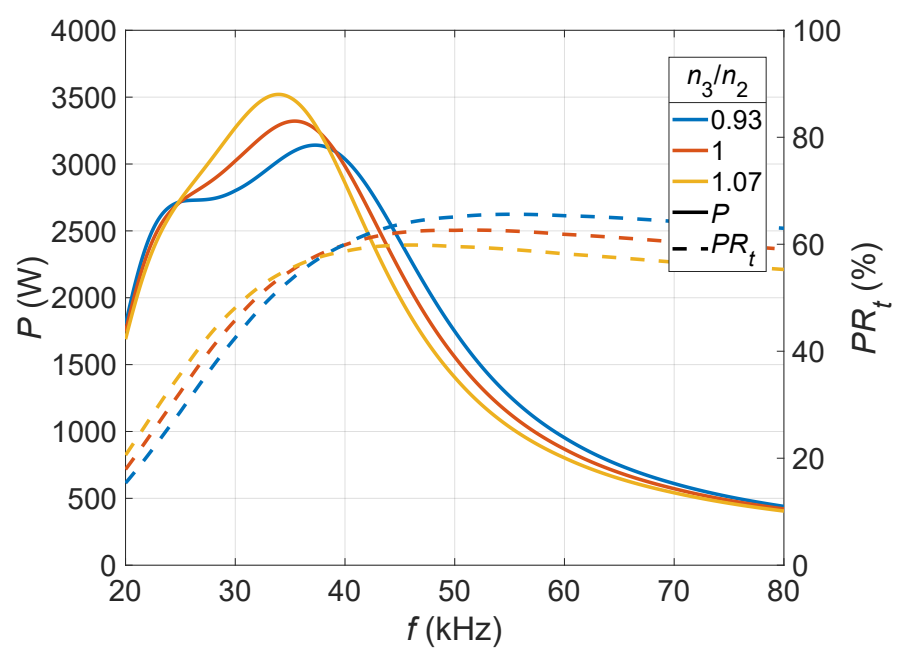

Fig. 9. Simulated power and power ratio variation with $n_{3} / n_{2}$.

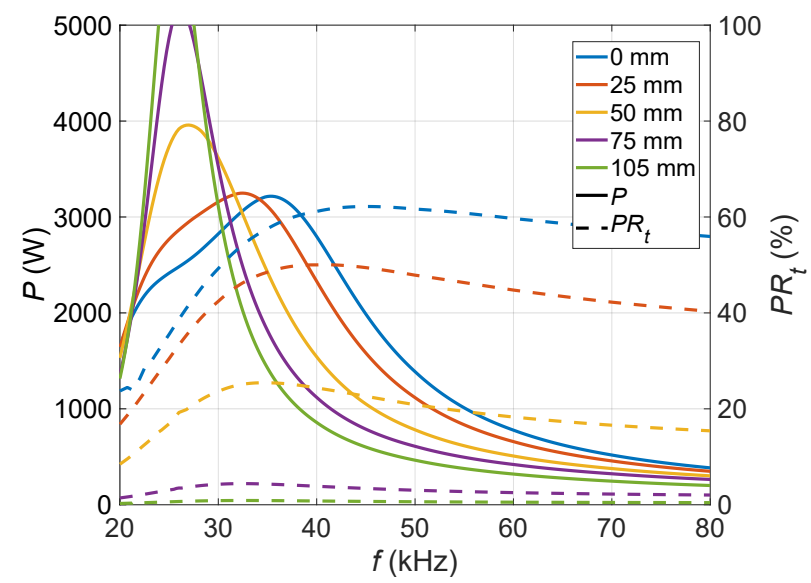

Fig. 10. $P$ and $P R_{t}$ variation with load misalignment.

and minimum $L_{\text {eq }}$, as seen on Figs. 5 and 6. These extreme values are related to the resonance of the receiver side, $\omega_{0, \text { rec }}$.

In most case maximum power, $P_{\max }$, is obtained at the global system's nance, $\omega_{0, \text { eq }}$. The power ratio is desired to remain constant up to $P_{\max }$, so global resonance has to be set at a slightly higher frequency than the receiver side resonance, which can be seen on Fig. 6 . On the one hand, when $\omega_{0, \text { rec }}$ is set at 20 and $30 \mathrm{kHz}, \omega_{0, \text { eq }}$ i pve $30 \mathrm{kHz}$ and $P R_{t}$ ranges between 50 and $60 \%$. On the rer hand, when $\omega_{0, \text { rec }}$ is set at 40 and $50 \mathrm{kHz}, \omega_{0, \text { eq }}$ low $30 \mathrm{kHz}$ and $P R_{t}$ ranges between 10 and $60 \%$. Moreo the receiver side resonance causes an inflection point in the power curve as well as the impedance extreme values in Fig. 5.

Combining equations (10) and (17), $Z_{\text {eq }}$ can be expressed in terms of single turn impedance matrix elements:

$$
Z_{\mathrm{eq}}=n_{1}^{2}\left(Z_{11 \text {,s.t. }}-\frac{Z_{12, \text { s.t. }}^{2}}{Z_{22, \text { s.t. }}+\frac{n_{3}^{2}}{n_{2}^{2}} Z_{33 \text {,s.t. }}}\right) .
$$

This expression shows that eceiver side inductors' number of turns only affect the g impedance by their relative values to each other. Moreover, for each fixed value of $n_{3} / n_{2}$

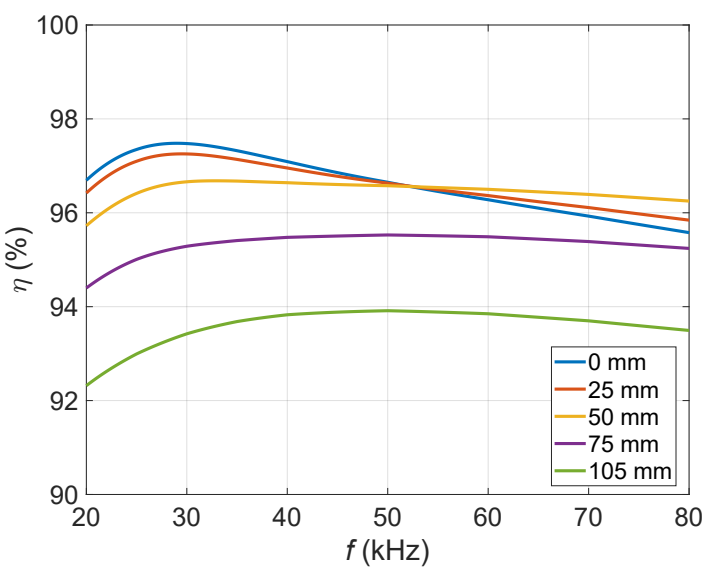

Fig. 11. Efficiency variation with load misalignment.

TABLE III

EXPERIMENTAL SYSTEM DESIGN PARAMETERS

\begin{tabular}{ccc}
\hline Inductor & $n_{i}$ & $C_{i}(\mathrm{nF})$ \\
\hline 1, primary & 17 & 1080 \\
2, secondary & 29 & 150 \\
3, tertiary & 29 & - \\
\hline
\end{tabular}

the impedance only depends on the primary inductor's number of turns.

The design process goes as follows. In order to be able to deliver $3000 \mathrm{~W}$ with near constant $P R_{t}$, the system must have a global resonance at higher frequency than receiver resonance and the equivalent resistance needs to satisfy $V_{o, \text { rms }}^{2} / R_{\mathrm{eq}}>$ $3000 \mathrm{~W}$ at global resonance [16], where $V_{o, \text { rms }}$ is the inverter output rms voltage. The half-bridge inverter uses a small DC bus capacitor, so its output voltage will essentially modulate the rectified mains voltage: $V_{o, \text { rms }}=\sqrt{2} / \pi V_{\text {mains,rms. }}$. In terms of number of turns and capacitor values, $C_{2, \text { s.t. }}$ can be selected to fix $\omega_{0, \text { rec }}$ at the desired value:

$$
C_{2, \text { s.t. }}=1 /\left(\omega_{0, \text { rec }}^{2}\left(L_{22, \text { s.t. }}+n_{3}^{2} / n_{2}^{2} L_{33, \text { s.t. }}\right)\right) \text {. }
$$

After selecting a potential $\omega_{0, \text { rec }}$, the designer must ensure that the $3000 \mathrm{~W}$ maximum power condition is met, as well as verify that $\omega_{0, \text { rec }}<\omega_{0, \text { eq }}$.

Since only the relative value of $n_{2}$ with $n_{3}$ affects global impedance, their absolute values can be used to freely select the ratio of inductor voltage and current when delivering the same power. The effects of the $n_{3} / n_{2}$ ratio on $P$ and $P R_{t}$ are shown in Fig. 9. An increase of the ratio increases $P_{\max }$ and $P R_{t}$ and reduces $\omega_{0, \text { eq }}$. In this case, $n_{2}=n_{3}$ has been chosen for simplicity, as it fulfills the $P R_{t}$ requirement using identical coils, simplifying the manufacturing process.

Usually, small adjustments need to be made in order to end up with an integer number of turns and available capacitor values. The prototype in this paper has a predetermined number of turns and capacitor for the primary inductor, 17 turns and $1080 \mathrm{nF}$, the selected number of turns for the second and third inductors are 29 turns, and the selected second capacitor has $150 \mathrm{nF}$. This results in a $\omega_{0, \text { eq }}$ of $35 \mathrm{kHz}$ and $\omega_{0, \text { rec }} 30 \mathrm{kHz}$. The system parameters are listed in Table III for convenience. 


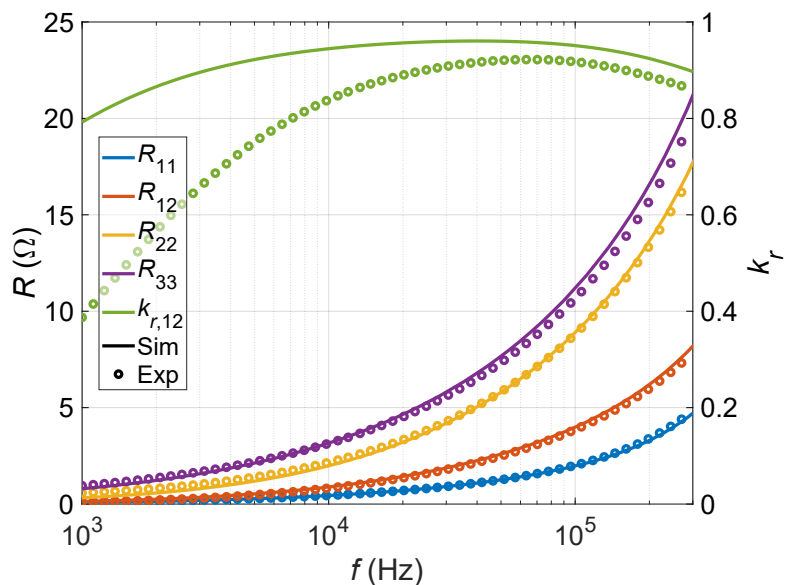

(a)

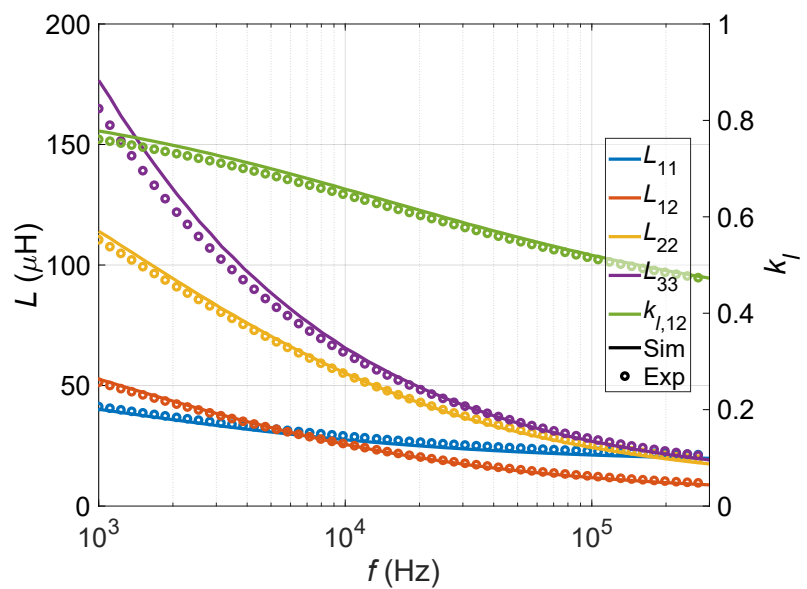

(b)

Fig. 12. Resistance (a) and inductance (b) of the impedance matrix elements measured by LCR.

A high number of turns was chosen for the second and third inductors to show that their absolute value would only affect the current and voltage ratio in the receiver side, and that the equivalent impedance would remain constant as long as the value $f$,s.t. was maintained by changing $C_{2}$ accordingly.

As 10 application, the system could be subjected to rapid movements by the user. Fig. 10 shows how $P$ and $P R_{t}$ changes with radial misalignment, illustrating that for any misalignment, the system will immediately reduce its power and power ratio. Moreover, the $P$ and $P R_{t}$ changes are significant even for displacements smaller than $25 \mathrm{~mm}$. Fortunaty, the simulated efficiency does not decrease considerably with misalignment, as shown in Fig. 11, where the minimum value remains above $93 \%$. Due to how the system works inherently, it does not need complex control to operate safely, and it is easy to detect misalignment and warn the user to correct it and maximize $P R_{t}$ again.

\section{EXPERIMENTAL MEASUREMENTS}

First, in order to verify the impedance simulation results, measurements of the impedance matrix have been taken in a small signal regime at several frequencies. Then, the system has been tested delivering full power to two ferromagnetic loads to validate the proposed design.

\section{A. Small signal regime}

A LCR meter has been used to measure self impedance of inductors one, two and three as well as the mutual impedance between one and two. Given that the third inductor is decoupled from the rest, as verified in the simulations, mutual impedances with the third inductor have not been considered.

While self impedances were measured directly, the mutual impedance was calculated from two indirect measurements. The difference between in-phase and opposite-phase measurements of the series connected inductors cancels out the self impedance contribution [1].

Fig. 12 shows simulated values with continuous lines and experimental values in dots. Most impedance curves show very

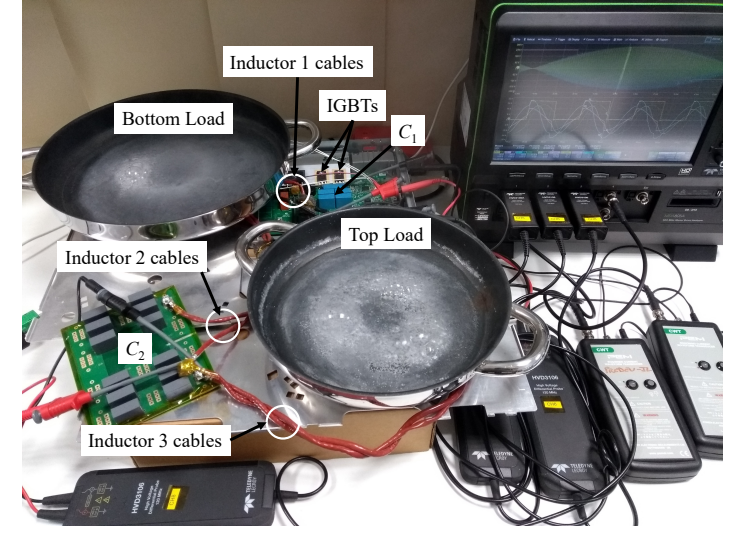

Fig. 13. Experimental setup with both bottom and top loads boiling water.

good agreement, with a maximum error of $7 \%$. The coupling factors, as indirect measurements, are more divergent.

Overall, these measurements verify the simulation accuracy for the given geometry and frequencies, with material properties congruent with small signal analysis. The results are encouraging to go ahead to the following full power test.

\section{B. Full power regime}

As mentioned in Section II, the system is fed by a halfbridge inverter, which modulates the rectified mains voltage [10]. The relevant parts of the simulated geometry stay the same, such as distances between inductors and loads, diameters and so on. However, in order to help heat dissipation in the experimental measurements and maint rromagnetic material properties with constant temperature $\curvearrowright$ independent load is a second water filled pan as seen on Fig. 13, flipping the top half of the small oven. This partition of the geometry is valid as long as each half maintains their relative geometry and materials of the original, and the inductors are kept far enough away to avoid coupling.

In the experimental setup,the first inductor is connected to the IH appliance's inverter and placed beneath the "bottom" 


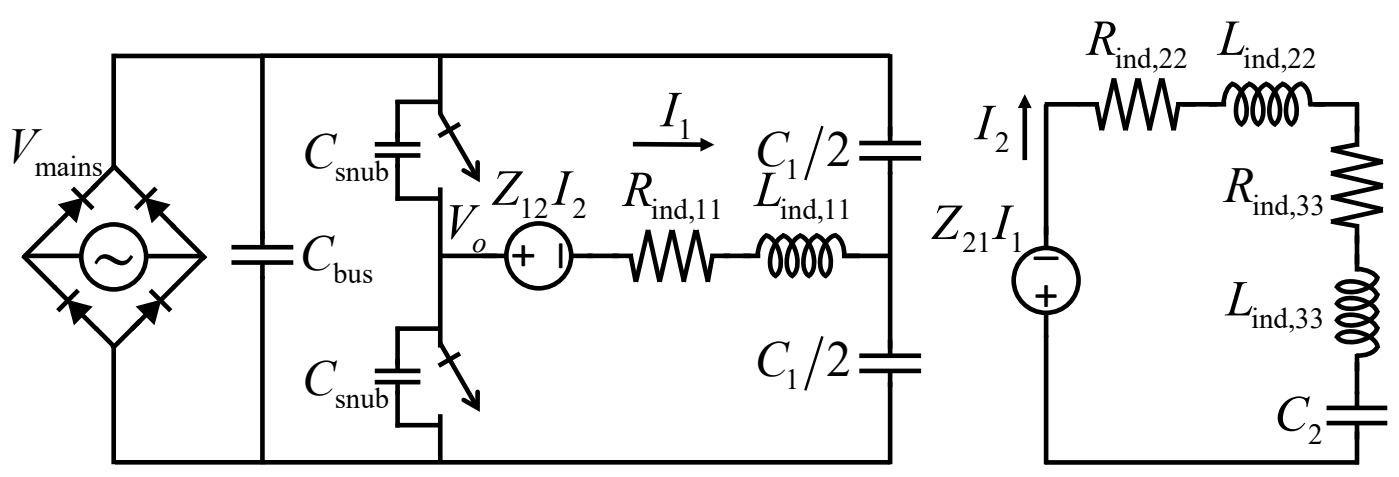

Fig. 14. Prototype's circuit diagram.

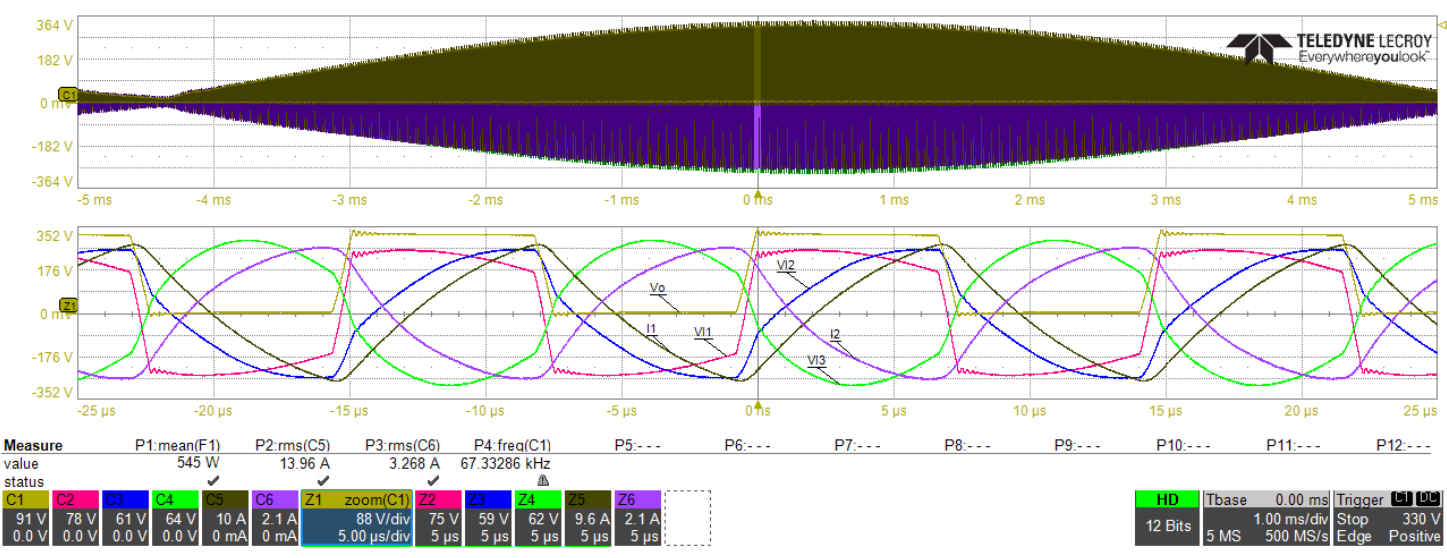

(a)
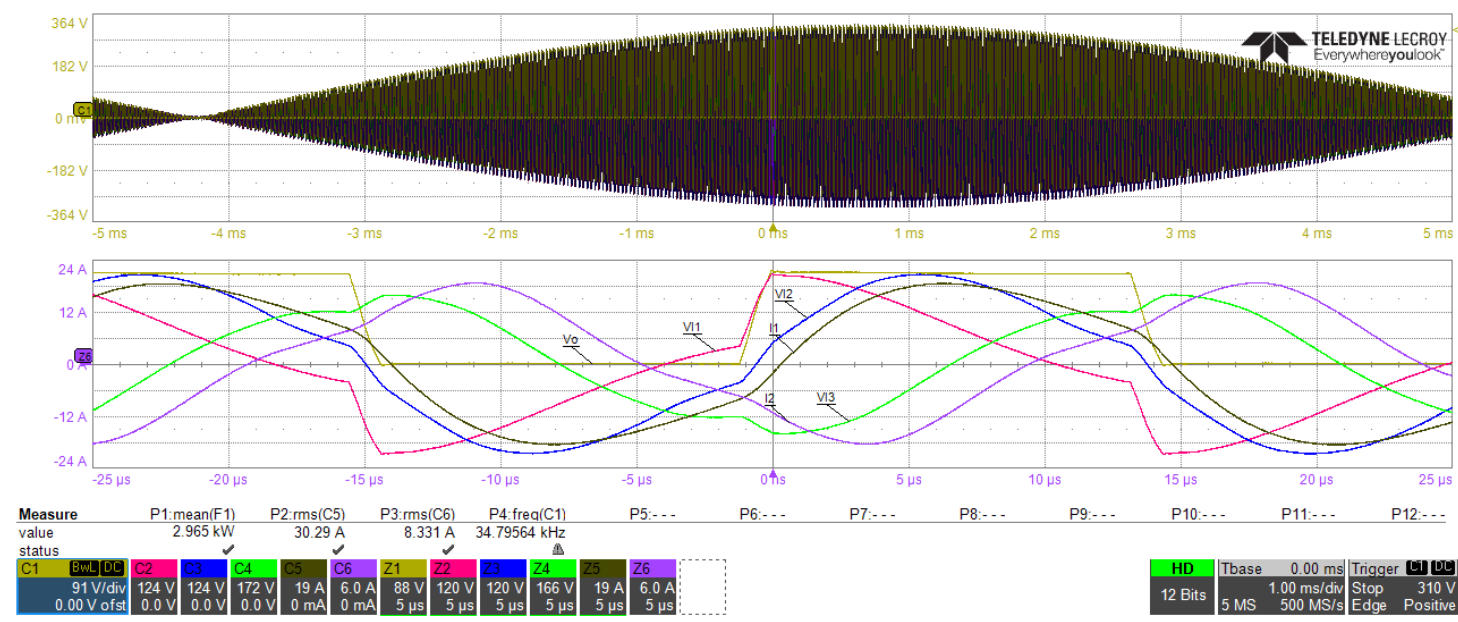

(b)

Fig. 15. Oscilloscope captures (a) 500 W, (b) 3000 W.

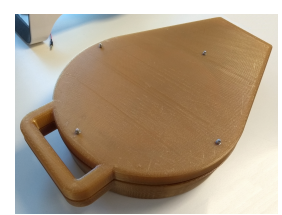

(a)

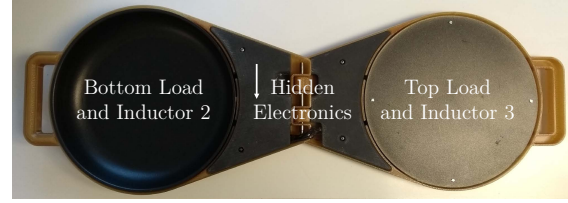

(b)

Fig. 16. Functional prototype: (a) closed lid (b) fully open.

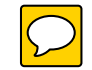

load. The second inductor is placed beneath the first inductor and the bottom load and connected to the $C_{2}$ capacitor board and the third inductor. The third inductor is likewise connected to the second inductor and the $C_{2}$ board, and it is placed beneath the "top" load.

The circuit diagram of the eom is shown in Fig. 14. The main differences with Fig. 3 are the voltage input to the system and the bifurcation of $C_{1}$. The mains voltage is rectified in a full diode bridge, it is filtered by a $3.3 \mu \mathrm{F}$ capacitor and it is inverted by a IGBT half- 


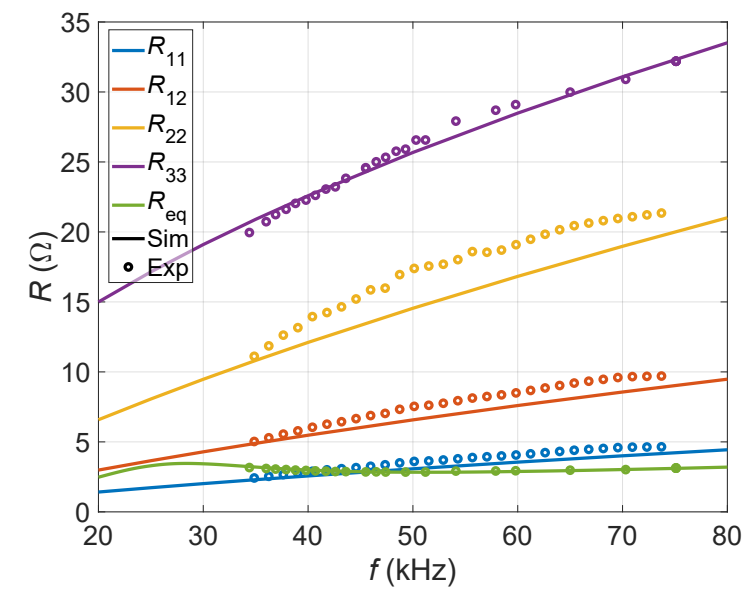

(a)

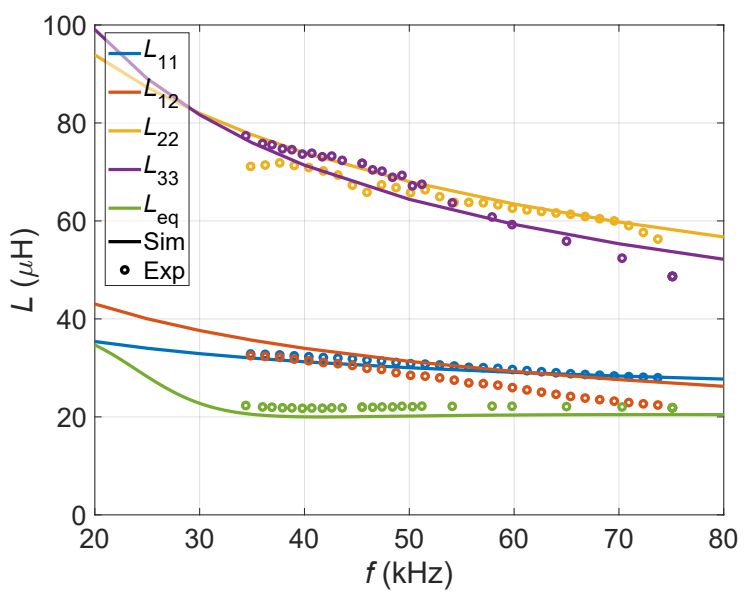

(b)

Fig. 17. Comparison between simulated and experimental impedance: (a) $R$ and (b) $L$.

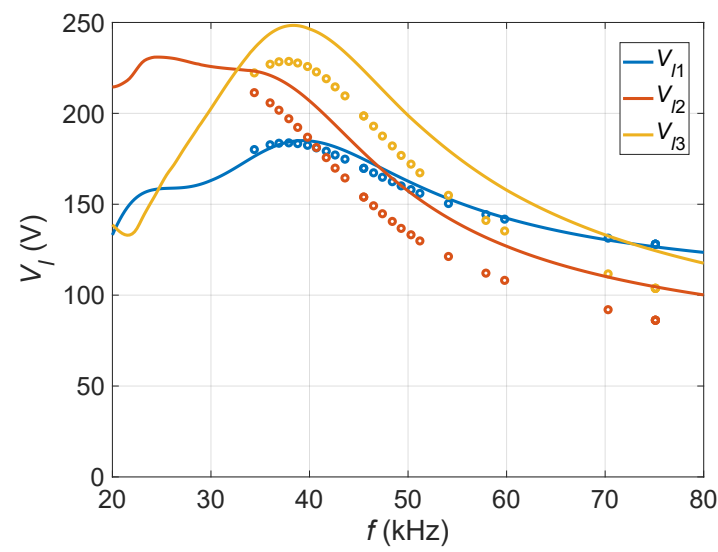

Fig. 18. Inductor voltages, both simulated and measured.

bridge inverter. The transistors use $15 \mathrm{nF}$ snubber capacitors to minimize turn-off losses. The $C_{1}$ capacitor is split to ensure zom voltage and eliminate all even harmonics.

e commercial cooktop has been used with frequency control to deliver power up to $3000 \mathrm{~W}$. Waveforms have been captured with an oscilloscope of inverter output voltage, $V_{o}$, primary inductor voltage, $V_{L 1}$, second inductor voltage, $V_{L 2}$, third inductor voltage, $V_{L 3}$, primary inductor current, $I_{1}$ and secondary inductor current, $I_{2}$. Sample captures when delivering $500 \mathrm{~W}$ and $3000 \mathrm{~W}$ are shown in Fig. 15. At low power, in Fig. 15 (a), the waveforms have almost triangular and exponential shapes, while at high power, in Fig 15 (b) the waveforms are more sinusoidal.

In addition to the experimental setup to take measurements, a functional prototype has also been built and shown in Fig. 16. The compartmentalization of the electronics and their position near the hinge, away from the loads, are enough to prevent the high temperatures from reaching the ceramic capacitors.

Calculations up to now have assumed the first order harmonic for its frequency calculations. In order to better determine the accuracy of the FEA simulations, the half-bridge inverter has been simulated in LTspice in order to obtain waveforms and electrical parameters.

The simulated circuit it of Fig. 14 with small modifications. Due to converge problems, the IGBTs are represented by ideal switches in the simulations. The inductive coupling is simulated with the built-in coupled inductor feature. (11) ng the component "ind2". The effect of the real part of the Imutual impedance is implemented as an arbitrary behavioural voltage source "bv", where the voltage induced by $i$ in $j, V_{r, i j}$, is generated by the mutual resistance, $R_{i j}$, and the current of the opposite inductor, $\underline{I}_{i}, V_{r, i j} \equiv \underline{R_{i j} I_{i}}$. The polarity of these elements had to be chosen carefully to produce valid results. A Matlab script was used to change impedance values for each frequency, run all simulations and store results.

Fourier transformations were used to calculate the experimental impedance values from inductor voltage, $V_{l i}$, and current, $I_{i}$, waveforms:

$$
\begin{aligned}
& Z_{\mathrm{eq}}=V_{l 1} / I_{1}, \\
& Z_{33}=V_{l 3} / I_{3} .
\end{aligned}
$$

$Z_{11}$ and $Z_{12}$ can be obtained from measurements with the receiver in open circuit, if $I_{2}=0$ :

$$
\begin{gathered}
Z_{\text {ind }, 11}=V_{l 1} / I_{1}, \\
Z_{12}=V_{l 2} / I_{1} .
\end{gathered}
$$

Knowing all other terms, $Z_{22}$ can be extracted from (10):

$$
Z_{22}=\frac{Z_{12}^{2}}{Z_{11}-Z_{\mathrm{eq}}}-Z_{33}
$$

The results are shown in Fig. 17, where the measured values are predicted for the most part by the FEA simulations.

Fig. 18 represents the simulated and measured inductor voltages. Fig. 19 represents the comparison between the simulated and measured values of power, power ratio and currents when the receiver side is either disconnected: (a) and (b), or connected: (c) and (d). Fig. 19 (a) shows that the $P$ peak at $\omega_{0, \text { eq }}$ is much higher than the desired $P_{\max }, 3000 \mathrm{~W}$. 


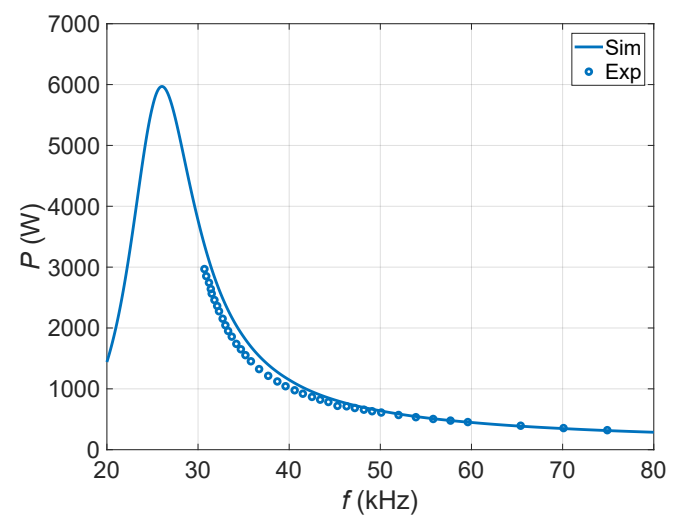

(a)

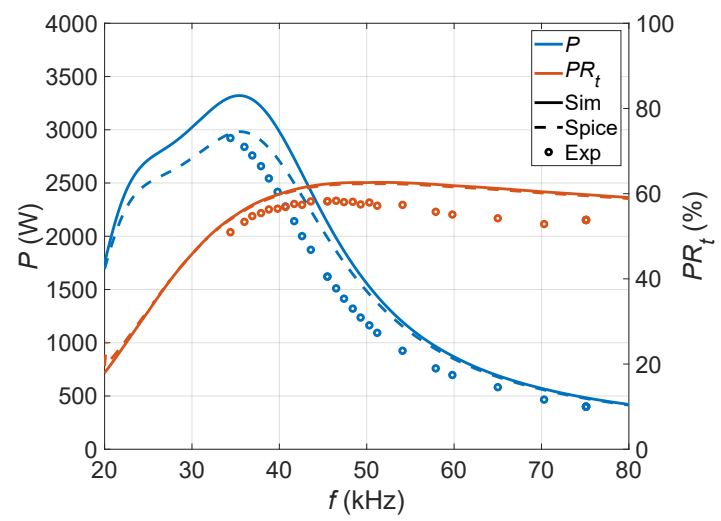

(c)

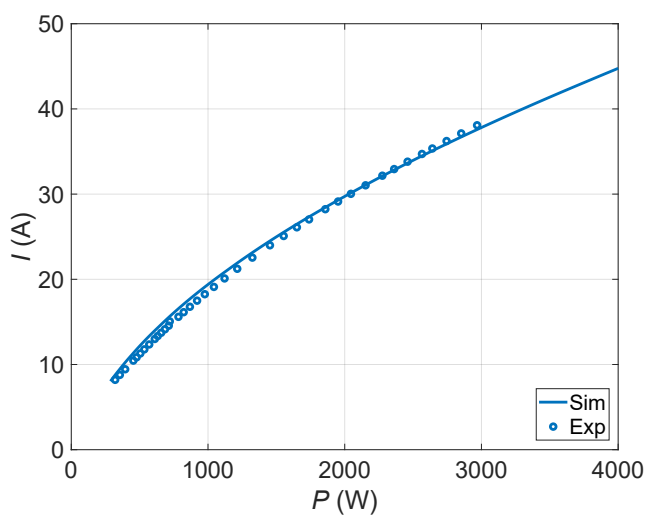

(b)

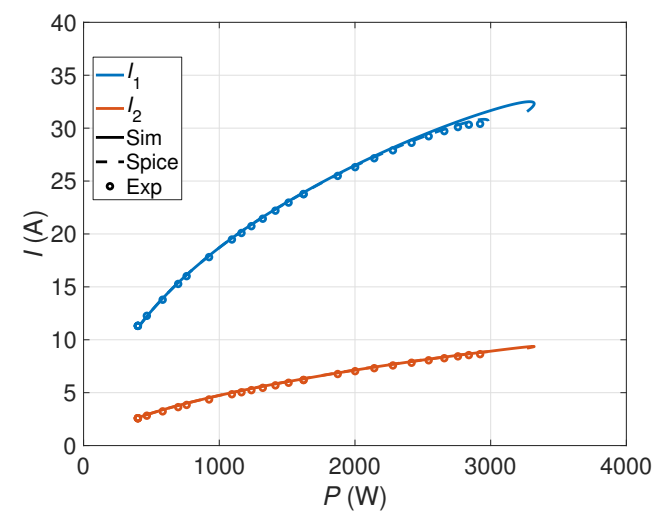

(d)

Fig. 19. Power measurements with a disconnected receiver: (a) $P$ (b) $I$. Measurements with connected receiver: (c) $P$ and $P R_{t}$ and (d) $I_{1}$ and $I_{3}$.

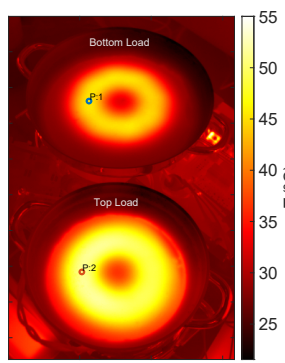

(a)

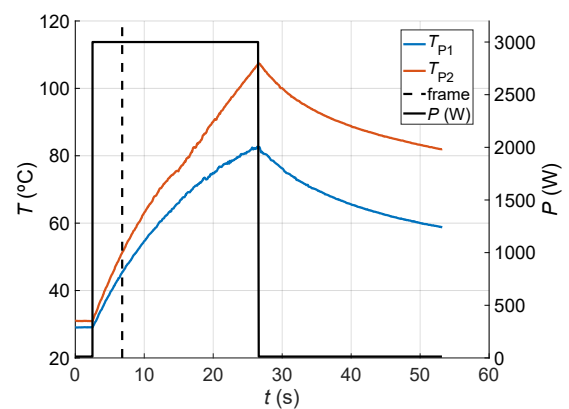

(b)
Fig. 20. Thermographic camera measurements with 3000 W. (a) Frame at $6.8 \mathrm{~s}$. (b) Temperature evolution of indicated points.

Consequently, the equivalent impedance is more inductive at $3000 \mathrm{~W}$ and more $I$ is required to deliver the same amount of power than the full system, as shown by comparing Fig. 19 (b) and (d). Therefore, reduction of time-average $P R_{t}$ can be achieved by disconnecting the receiver, bearing in mind that high power could be too stressful to the electronics. In Fig. 19 (c), the small error in $L_{\mathrm{eq}}$ causes a shift of $\omega_{0, \mathrm{eq}}$ and a slight reduction of $P R_{t}$, but otherwise simulations were able to predict the experimental results, confirming the validity of the calculation and design method.

As a result of a $P R_{t}$ higher than $50 \%$, more than half of

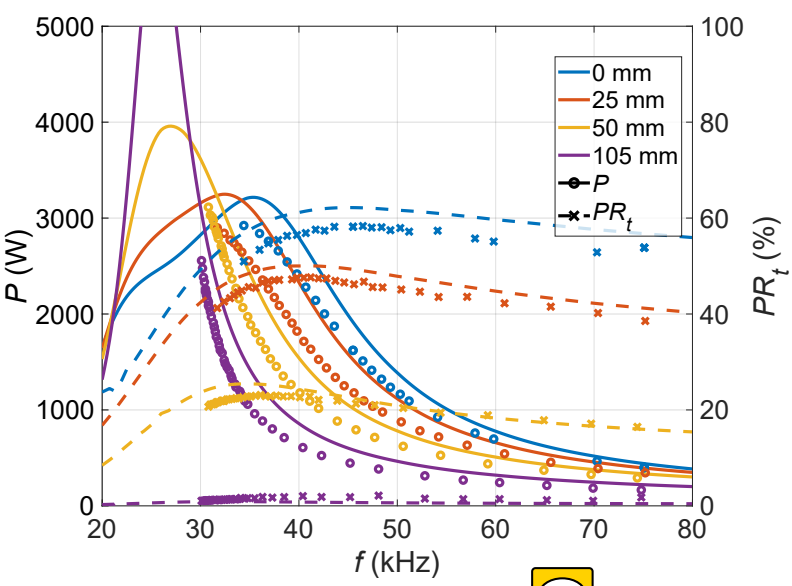

Fig. 21. Measured $P$ and $P R_{t}$ variation with

the total power goes to the top load, which is qualitatively shown in Fig. 16 with the bubble density of the boiling water. For further confirmation, Fig. 20 shows the temperature distribution with a thermographic camera when $3000 \mathrm{~W}$ are applied to the system with empty vessels until $100^{\circ} \mathrm{C}$ are reached.

Fig. 21 shows experimental measurements of $P$ and $P R_{t}$ with radial misalignment. The measurements confirm the validity of the simulations. 


\section{CONCLUSIONS}

The simulations and analytical calculations presented in this paper show that induction heating and inductive coupling can be used in conjunction to deliver power to multiple ferromagnetic loads with a single source in an uncommon IH application. A le cooktop inductor can be used to heat two different loads $\Omega$ adequate power ratio. This allows heating uncoupled elements that are not directly placed on top of the cooktop or extending the heating zone for long vessels, such as rectangular grills.

The experimental verification affirms the accuracy of the simulated impedance matrix. In order to maintain a consistent power ratio, global system resonant frequency must be higher than the receiver side resonant frequency. The ratio between turns of the second and third inductors can be used to modify the power ratio, though their absolute value does not affect equivalent impedance. This degree of freedom can be used to select the relative voltage and current in the receiver side. Full power delivery measurements clearly verify the simulations, with only a small shift in resonant frequency and a small reduction in calculated power ratio.

Considering that the power ratio between both loads is currently fixed by geometry and design, further steps should be taken to be able to control the amount of power delivered to each load. For example a switch in the receiver side could be used to change between operating in a conventional IH configuration with the primary inductor only and the full ICH configuration. The addition of independent power control could also lead to food temperature control inside the oven with additional sensors and electronics.

System misalignment reduces power delivery to the top load, but the system can still operate safely and efficiently. Therefore, the misalignment can be detected and communicated to the user, so that they may correct it. Future work could investigate the compatibility of this kind of system with total active surface cooktops to completely mitigate the misalignment problem.

\section{REFERENCES}

[1] E. Plumed, I. Lope, J. Acero, and J. M. Burdío, "Design of a three inductor system with one externally fed for an inductively coupled heating application," in Proc. IECON 2019 - 45th Annual Conf. of the IEEE Industrial Electronics Society, vol. 1, DOI 10.1109/IECON.2019.8927098, pp. 5070-5074, Oct. 2019.

[2] J. Acero, J. M. Burdio, L. A. Barragan, D. Navarro, R. Alonso, J. Ramon, F. Monterde, P. Hernandez, S. Llorente, and I. Garde, "Domestic induction appliances," IEEE Ind. Appl. Mag., vol. 16, DOI 10.1109/MIAS.2009.935495, no. 2, pp. 39-47, Mar. 2010.

[3] T. Mishima, C. Takami, and M. Nakaoka, "A new current phasorcontrolled ZVS twin half-bridge high-frequency resonant inverter for induction heating," IEEE Trans. Ind. Electron., vol. 61, DOI 10.1109/TIE.2013.2274420, no. 5, pp. 2531-2545, May. 2014.

[4] M. Souley, J. Egalon, S. Caux, O. Pateau, Y. Lefèvre, and P. Maussion, "Optimization of the settings of multiphase induction heating system," IEEE Trans. Ind. Appl., vol. 49, DOI 10.1109/TIA.2013.2264924, no. 6, pp. 2444-2450, Nov. 2013.

[5] V. Esteve, J. Jordán, E. Sanchis-Kilders, E. J. Dede, E. Maset, J. B. Ejea, and A. Ferreres, "Enhanced pulse-density-modulated power control for high-frequency induction heating inverters," IEEE Trans. Ind. Electron., vol. 62, DOI 10.1109/TIE.2015.2436352, no. 11, pp. 6905-6914, Nov. 2015.
[6] L. Meng, K. W. E. Cheng, and K. W. Chan, "Systematic approach to high-power and energy-efficient industrial induction cooker system: Circuit design, control strategy, and prototype evaluation," IEEE Trans. Power Electron., vol. 26, DOI 10.1109/TPEL.2011.2165082, pp. 37543765, 2011.

[7] I. Lope, J. Acero, and C. Carretero, "Analysis and optimization of the efficiency of induction heating applications with litz-wire planar and solenoidal coils," IEEE Trans. Power Electron., vol. 31, no. 7, pp. 50895101, 2016.

[8] E. Plumed, J. Acero, I. Lope, and J. M. Burdío, "Design methodology of high performance domestic induction heating systems under worktop," IET Power Electron., vol. 13, DOI 10.1049/iet-pel.2019.0693, pp. 300306, 2020.

[9] J. Villa, J. I. Artigas, J. R. Beltrán, A. D. Vicente, and L. A. Barragán, "Analysis of the acoustic noise spectrum of domestic induction heating systems controlled by phase-accumulator modulators," IEEE Trans. Ind. Electron., vol. 66, DOI 10.1109/TIE.2018.2870351, no. 8, pp. 59295938, Aug. 2019.

[10] O. Lucía, P. Maussion, E. J. Dede, and J. M. Burdío, "Induction heating technology and its applications: Past developments, current technology, and future challenges," IEEE Trans. Ind. Electron., vol. 61, DOI 10.1109/TIE.2013.2281162, no. 5, pp. 2509-2520, May. 2014.

[11] H.-P. Park and J.-H. Jung, "Load-adaptive modulation of a seriesresonant inverter for all-metal induction heating applications," IEEE Trans. Ind. Electron., vol. 65, DOI 10.1109/TIE.2018.2793270, pp. 6983-6993, 2018.

[12] C. Carretero, O. Lucía, J. Acero, and J. M. Burdío, "Fea tool based model of partly coupled coils used in domestic induction cookers," in Proc. IECON 2011 - 37th Annual Conf. of the IEEE Industrial Electronics Society, DOI 10.1109/IECON.2011.6119708, pp. 2533-2538, Nov. 2011.

[13] J. Acero, C. Carretero, I. Millán, . Lucía, R. Alonso, and J. M. Burdío, "Analysis and modeling of planar concentric windings forming adaptable-diameter burners for induction heating appliances," IEEE Trans. Power Electron., vol. 26, DOI 10.1109/TPEL.2010.2085453, no. 5, pp. 1546-1558, 2011.

[14] C. Carretero, O. Lucia, J. Acero, and J. M. Burdio, "Computational modeling of two partly coupled coils supplied by a double half-bridge resonant inverter for induction heating appliances," IEEE Trans. Ind. Electron., vol. 60, DOI 10.1109/TIE.2012.2202360, no. 8, pp. 30923105, Aug. 2013.

[15] H. N. Pham, H. Fujita, K. Ozaki, and N. Uchida, "Estimating method of heat distribution using 3-d resistance matrix for zone-control induction heating systems," IEEE Trans. Power Electron., vol. 27, DOI 10.1109/TPEL.2011.2179984, pp. 3374-3382, 2012.

[16] J. Serrano, I. Lope, and J. Acero, "Nonplanar overlapped inductors applied to domestic induction heating appliances," IEEE Trans. Ind. Electron., vol. 66, DOI 10.1109/TIE.2018.2880721, pp. 6916-6924, 2019.

[17] A. Dominguez, L. A. Barragan, J. I. Artigas, A. Otin, I. Urriza, and D. Navarro, "Reduced-order models of series resonant inverters in induction heating applications," IEEE Trans. Power Electron., vol. 32, DOI 10.1109/TPEL.2016.2559160, no. 3, pp. 2300-2311, 2017.

[18] H. Sarnago, P. Guillén, J. M. Burdío, and O. Lucia, "Multiple-output zvs resonant inverter architecture for flexible induction heating appliances," IEEE Access, vol. 7, DOI 10.1109/ACCESS.2019.2950346, pp. $157046-157056,2019$.

[19] J. Davies and P. Simpson, Induction heating handbook. McGraw-Hill Companies, 1979.

[20] M. K. Kazimierczuk, High-frequency magnetic components. John Wiley \& Sons, 2009.

[21] G. A. Covic and J. T. Boys, "Inductive power transfer," Proc. IEEE, vol. 101, DOI 10.1109/JPROC.2013.2244536, no. 6, pp. 1276-1289, Jun. 2013.

[22] J. Garnica, R. A. Chinga, and J. Lin, "Wireless power transmission: From far field to near field," Proc. IEEE, vol. 101, DOI 10.1109/JPROC.2013.2251411, no. 6, pp. 1321-1331, Jun. 2013.

[23] J. Huang, Y. Zhou, Z. Ning, and H. Gharavi, "Wireless power transfer and energy harvesting: Current status and future prospects," IEEE Wireless Commun. Mag., vol. 26, DOI 10.1109/MWC.2019.1800378, no. 4, pp. 163-169, Aug. 2019.

[24] T. Kan, T.-D. Nguyen, J. C. White, R. K. Malhan, and C. C. Mi, "A new integration method for an electric vehicle wireless charging system using lcc compensation topology: Analysis and design," IEEE Trans. Power Electron., vol. 32, DOI 10.1109/TPEL.2016.2552060, pp. 1638-1650, 2017. 
[25] N. Khan, H. Matsumoto, and O. Trescases, "Wireless electric vehicle charger with electromagnetic coil-based position correction using impedance and resonant frequency detection," IEEE Trans. Power Electron., vol. 35, DOI 10.1109/tpel.2020.2965476, no. 8, pp. 7873-7883, 2020.

[26] Y. Jiang, L. Wang, J. Fang, C. Zhao, K. Wang, and Y. Wang, “A joint control with variable zvs angles for dynamic efficiency optimization in wireless power transfer system," IEEE Trans. Power Electron., vol. 35, DOI 10.1109/TPEL.2020.2977849, no. 10, pp. 11 064-11 081, 2020.

[27] F. J. López-Alcolea, J. V. d. Real, P. Roncero-Sánchez, and A. P. Torres, "Modeling of a magnetic coupler based on single- and double-layered rectangular planar coils with in-plane misalignment for wireless power transfer," IEEE Trans. Power Electron., vol. 35, no. 5, pp. 5102-5121, 2020.

[28] W. Han, K. T. Chau, C. Jiang, and W. Liu, "All-metal domestic induction heating using single-frequency double-layer coils," IEEE Trans. Magn. vol. 54, DOI 10.1109/TMAG.2018.2846548, no. 11, pp. 1-5, Nov. 2018.

[29] E. Plumed, I. Lope, J. Acero, and J. M. Burdio, "Inductor system evaluation for simultaneous wireless energy transfer and induction heating," in Proc. IECON 2018 - 44th Annual Conf. of the IEEE Industrial Electronics Society, DOI 10.1109/IECON.2018.8591416, pp. 3509-3514, Oct. 2018.

[30] R. C. M. Gomes, M. A. Vitorino, D. A. Acevedo-Bueno, and M. B. de Rossiter Corrêa, "Multiphase resonant inverter with coupled coils for ac-ac induction heating application," IEEE Trans. Ind. Appl., vol. 56, DOI 10.1109/TIA.2019.2955661, pp. 551-560, 2020.

[31] W. Han, K. T. Chau, and Z. Zhang, "Flexible induction heating using magnetic resonant coupling," IEEE Trans. Ind. Electron., vol. 64, DOI 10.1109/TIE.2016.2620099, no. 3, pp. 1982-1992, Mar. 2017.

[32] W. Han, K. T. Chau, Z. Zhang, and C. Jiang, "Single-source multiplecoil homogeneous induction heating," IEEE Trans. Magn., vol. 53, DOI 10.1109/TMAG.2017.2717867, no. 11, pp. 1-6, Nov. 2017.

[33] E. Plumed, I. Lope, and J. Acero, "Induction heating adaptation of a different-sized load with matching secondary inductor to achieve uniform heating and enhance vertical displacement," IEEE Trans. Power Electron., vol. 36, DOI 10.1109/TPEL.2020.3033833, no. 6, pp. 69296942, 2021

[34] M. Kim, H. Park, and J. Jung, "Practical design methodology of ih and ipt dual-functional apparatus," IEEE Trans. Power Electron., vol. 35, DOI 10.1109/TPEL.2020.2976054, no. 9, pp. 8897-8901, 2020.

[35] J. Sakellaris, G. Meunier, A. Raizer, and A. Darcherif, "The impedance boundary condition applied to the finite element method using the magnetic vector potential as state variable: a rigorous solution for high frequency axisymmetric problems," IEEE Transactions on Magnetics, vol. 28, DOI 10.1109/20.124016, no. 2, pp. 1643-1646, Mar. 1992. 